\title{
Multifuncionalidad y retos de futuro en el paisaje cultural del regadío del Bajo Ter
}

\author{
David Pavón ${ }^{1}$, Francesco Visentin ${ }^{2}$, Anna Ribas ${ }^{1}$ y Francesco Vallerani ${ }^{3}$ \\ 1 Departamento de Geografía, Universitat de Girona \\ ${ }^{2}$ Dipartimento di Scienze Storiche, Geografiche e dell'antichitá \\ Universitá degli Studi di Padova \\ ${ }^{3}$ Dipartimento di Economia, Universitá Ca'Foscari. Venezia
}

david.pavon@udg.edu, franc.visentin@gmail.com, anna.ribas@udg.edu, ramusa@unive.it,

\begin{abstract}
Resumen. El paisaje actual del Bajo Ter es el resultado de una red de canales molineros y de irrigación que se remontan a la Edad Media. El agua que circula por estos canales adquiere un nuevo valor de uso, que es a la vez económico, ecológico y social. Sin embargo, la reciente ejecución, a partir de 2008, del proyecto de canalización y soterramiento del regadío tradicional, con el objetivo de mejorar la eficiencia en el uso del agua, ha desencadenado un interesante debate social respecto a qué queremos y qué podemos conservar de estos paisajes tradicionales del regadío y, en el caso de que se llegue a un acuerdo, cómo vamos a gestionarlo y quién va a hacerlo. La propuesta de comunicación pretende analizar las dinámicas apuntadas y los retos de presente y de futuro a los que debe hacer frente el regadío en la zona. A este respecto se prestará especial atención al papel multifuncional que pueden desempeñar los canales tradicionales, sea desde el punto de vista productivo, ambiental, patrimonial, turístico, de calidad de vida, etc. También se fijará la atención en cómo ha evolucionado la gestión de los canales a través del tiempo. De forma complementaria se apuntarán algunas influencias que pueden ejercer al respecto nuevas herramientas de políticas sectoriales y de la legislación, sea en materia de aguas o de paisaje.
\end{abstract}

Palabras clave: paisaje cultural, regadío, Bajo Ter, multifuncionalidad, modernización.

\begin{abstract}
The current landscape of the Baix Ter is the result of a network of miller and irrigation canals dating back to the Middle Ages. The water flowing through these channels acquires a new value in use which is economic, ecological and social at the same time. However, the recent carrying out of the piping and underground works of traditional irrigation from 2008, with the aim of improving efficiency in water use, has triggered an interesting social debate about what we want and what we can conserve of these traditional irrigation landscapes and, in the event that an agreement is reached, how we manage it and who will do it. The proposed paper tries to analyze the dynamics and challenges of present and of future which it must face the irrigation in the area. In this regard we will pay a particular attention to the multifunctional role that traditional canals can carry out, either from the point of view of production, environment, heritage, tourism, quality of life, etc. The attention will be fixed in how it has evolved the management of the canals across the time too. Complementary will be described some influences that can exercise in the matter on that subject new tools of sectorial policies and legislation as water or landscape.
\end{abstract}

Keywords: cultural landscape, irrigation, Baix Ter, multifunctionality, modernization.

\section{Introducción}

La reorganización y el control de los flujos hídricos figuran entre los aspectos más significativos de la transformación humana del medio natural. Los cursos de agua no constituyen solo una preciada dotación ambiental, sino que además representan unos trazados lineales de elevado interés cultural donde, gracias a la interacción entre soporte natural e intervenciones antrópicas, podemos identificar una gran variedad de tipologías paisajísticas.

Actualmente, son numerosos los estudiosos realizados desde la Geografía que entienden los paisajes del agua no solo como las formas en que los grupos humanos perciben la propia realidad, sino también como factores clave de la transformación intelectual y material de la naturaleza. Los paisajes del agua son sistemas de verificación privilegiados, 
delicados y multiescalares, donde los valores colectivos se superponen a los individuales y donde el concepto de artefacto confluye con el de patrimonio para desembocar en el propio de paisaje. Los canales artificiales se convierten, de esta manera, en una oportunidad para asegurar que el recurso hídrico y la red hidrográfica se incorporen a los programas territoriales, a los planes urbanísticos y paisajísticos, a las políticas sectoriales concretas y, en general, a cualquier intervención en la que intervengan aspectos ambientales, culturales, sociales e hidráulicos.

En este sentido, la presente comunicación se centra en la capacidad de transformación que tiene el agua en un territorio determinado, como el Baix Ter (Catalunya, España) y a la huella dejada por diversas dinámicas históricas que han contribuido, durante siglos, a la configuración de un espacio que es dinámico. Ello permite que nos movamos dentro del concepto de paisaje, que tiene muchos aspectos teóricos de importancia fundamental para el estudio de la geografía cultural. En este sentido han sido fundamentales las contribuciones de Neil Smith (1984) y de Henri Lefebvre (1991). En el caso de los canales artificiales ofrecen una perspectiva desafiante para el estudio de la compleja malla hidrográfica que, por capilaridad, ha "diseñado" el mosaico del paisaje. Se pone el énfasis en una zona privilegiada donde la evolución geo-histórica, si bien por un lado ha reducido progresivamente la libre expansión de dinámica natural, por otra parte dispone de una sugestiva morfología antrópica resultado de las oportunidades ofrecidas por la presencia fluvial. El paisaje es un teatro en el que ciertos grupos sociales se han estructurado históricamente en un estrecho vínculo con el espacio y con otros grupos de personas estableciendo una socialización continuada. En este proceso la capacidad implícita de producir conocimiento y progreso es clara.

En esta contribución se va a examinar el paisaje del agua en el ámbito del Baix Ter, formado a lo largo de los tiempos, en particular, entre los siglos XVI y XVIII, cuando la consolidación de los canales molineros como canales de riego va a contribuir decisivamente a la vertebración del territorio en su conjunto. El análisis se llevará a cabo teniendo en cuenta los dos canales más importantes abiertos gracias a las derivaciones de los caudales del curso bajo del río Ter: el rec (acequia en español) de Sentmenat y el rec del Molí de Pals. La primera parte del análisis centrará la atención en el proceso geo-histórico que ha permitido a estos canales llegar hasta el presente sin experimentar grandes cambios y manteniendo su uso secular. A continuación van a abordarse los proyectos para su modernización iniciados en 2008 por sus respectivas comunidades de regantes. Se trata de unas intervenciones que, aunque persiguen aumentar la eficiencia y el ahorro en el consumo de agua, amenazan con desestabilizar el equilibrio paisajístico y funcional de la zona. Estas obras serán estudiadas enmarcándolas en el panorama de algunas políticas europeas y locales con capacidad de incidencia directa, incluyéndose aquí la Convención Europea del Paisaje (año 2000) y de su traducción, a escala catalana, con la creación del Observatorio del Paisaje de Catalunya (año 2005). También se incidirá en el papel que ha jugado al respecto un ente como el Consorcio Alba-Ter, integrado por la mayoría de los municipios ribereños de dicho curso fluvial.

\section{Marco geográfico y canales de irrigación en el Baix Ter}

El Ter nace en la cordillera de los Pirineos a unos 2.400 metros de altitud, en el noreste de Catalunya y desemboca en el Mediterráneo después de salvar una distancia de 208 kilómetros. El conjunto de su cuenca cubre aproximadamente $3.010 \mathrm{~km}^{2}$ y es el río más 
largo que discurre en su totalidad en territorio catalán. Junto con el Llobregat constituye una de las vías fluviales más importantes de la historia económica y social de la región.

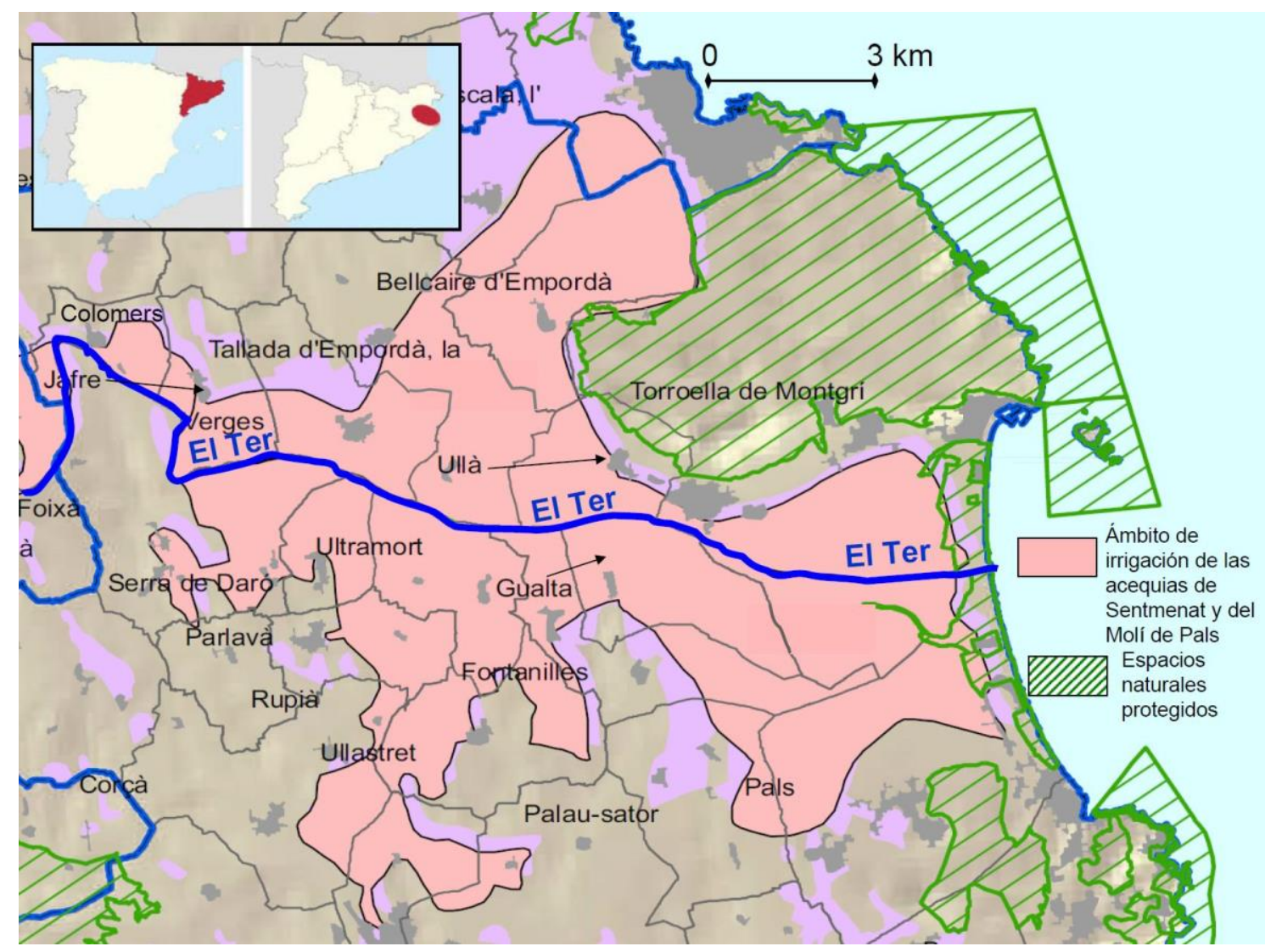

Fig. 1. Ámbito de irrigación de las acequias de Sentmenat y del Molí de Pals ${ }^{1}$.

El ámbito geográfico conocido como Baix Ter (comarca del Baix Empordà, provincia de Girona) se estructura a través del eje principal que es el río Ter. De hecho se corresponde con la llanura que se extiende a ambas márgenes en sus últimos 20 kilómetros, desde el pueblo de Colomers hasta alcanzar su desembocadura en la playa de Pals. Los usos agrícolas son dominantes y se articulan gracias a un complejo entramado de acequias y canales que derivan y distribuyen el agua necesaria para abastecer una extensión irrigable de unas 6.000 ha. (ver figura 1). Según los datos recogidos en 2009 para la definición de la unidad de paisaje del Baix Ter-Empordanet, incluida en el Catálogo de Paisaje de las comarcas gerundenses, este territorio comprendía unos $250 \mathrm{~km}^{2}$. De ellos, alrededor de un $66 \%$ eran tierras de cultivo, el 28,3\% correspondería a la vegetación espontánea, un 4,7\% áreas construidas y el restante 1\% pertenecería a las láminas de agua y a la morfología litoral. Esta distribución porcentual da una idea de la relevancia de los campos de cultivo.

La zona del Baix Ter comprende alrededor de una cuarentena de núcleos de población, algunos de ellos con siglos de historia, otros bastante más recientes; en total, unos 30.000 habitantes. Algunos pequeños núcleos rurales (Gualta, Fontanilles, Verges, Ullà, Bellcaire,

\footnotetext{
${ }^{1}$ Fuente: adaptación a partir de IGREMAP, S.L.P. (2010): Pla de Regadius de Catalunya 2008-20
} 
Jafre, Colomers, Canet de la Tallada, etc.) se reparten por el interior de esta extensa llanura agrícola en la que Torroella de Montgrí ejerce de capital de referencia, mientras que en primera línea de mar núcleos turísticos como L'Estartit o Pals, éste último un poco más alejado, coexisten con los últimos vestigios de humedales litorales del Baix Ter (la PleteraTer Vell y Basses d'en Coll).

\subsection{Origen, evolución y uso de los canales en el Baix Ter}

La construcción de canales para el transporte de agua en el Baix Ter se remonta a la Edad Media, si bien será durante los siglos XVII y XVIII cuando esta red de acequias y canales se consolide plenamente (Albertí y Roura 2002). Las principales acequias serían el canal de Sentmenat, la acequia del Molí de Pals; otras más secundarias son las del canal del Ter Vell, la riera Nueva, la riera Grossa de Pals, el canal d'Es Coll y el canal de la Tallada o de la Montaña.

Junto con las presas y otras infraestructuras hidráulicas concebidas para el control y la regulación del caudal circulante, los canales del Baix Ter se han utilizado, a lo largo de los tiempos, para diversas finalidades que van desde la irrigación de cultivos hasta mover molinos, generar electricidad, drenar las aguas de las tierras de cultivo, etc. En general, un mismo canal o acequia podía abastecer de agua a diferentes aprovechamientos a lo largo de su trayecto. Por su relevancia y capacidad para estructurar los aprovechamientos hídricos del territorio, nos centraremos básicamente en las dos grandes acequias que atraviesan la llanura del Baix Ter: el canal de Sentmenat y la acequia del Molí de Pals (ver figura 2).

El origen de los canales se asocia, fundamentalmente, a las necesidades energéticas de los molinos harineros. Los derechos de la acequia del Molí de Pals así como los de los molinos que alimentaba -el molino de Gualta y el molino de Pals- eran propiedad del conde de Peralada, sucesor del conde de Empúries. En relación al canal de Sentmenat, el barón de Verges tenía en propiedad los derechos de este canal así como de lo de un molino en Jafre (molino de Palol, actualmente desaparecido), el molino de Verges y otro en Bellcaire. La existencia de la actual presa de esta acequia parece ser que se remonta a 1458 por concesión otorgada por el rey Juan II, aunque hay constancia documental de una más primitiva del año 1224.

Será a partir de los siglos XVII y XVIII, momento de introducción de nuevos cultivos y técnicas agrarias que mejoran la productividad de las tierras, cuando los canales empezarán a ser utilizados para el regadío. Posteriormente, a finales del siglo XIX y principios del XX los molinos se transforman en pequeñas centrales hidroeléctricas. Su energía irá destinada, a partir de entonces, a proporcionar la fuerza necesaria a los molinos harineros y especialmente a iluminar núcleos de población. Sin embargo, a partir de mediados del siglo pasado se inicia una tendencia al abandono progresivo de estas pequeñas centrales hidroeléctricas, cuando entran en juego las grandes centrales productoras. 


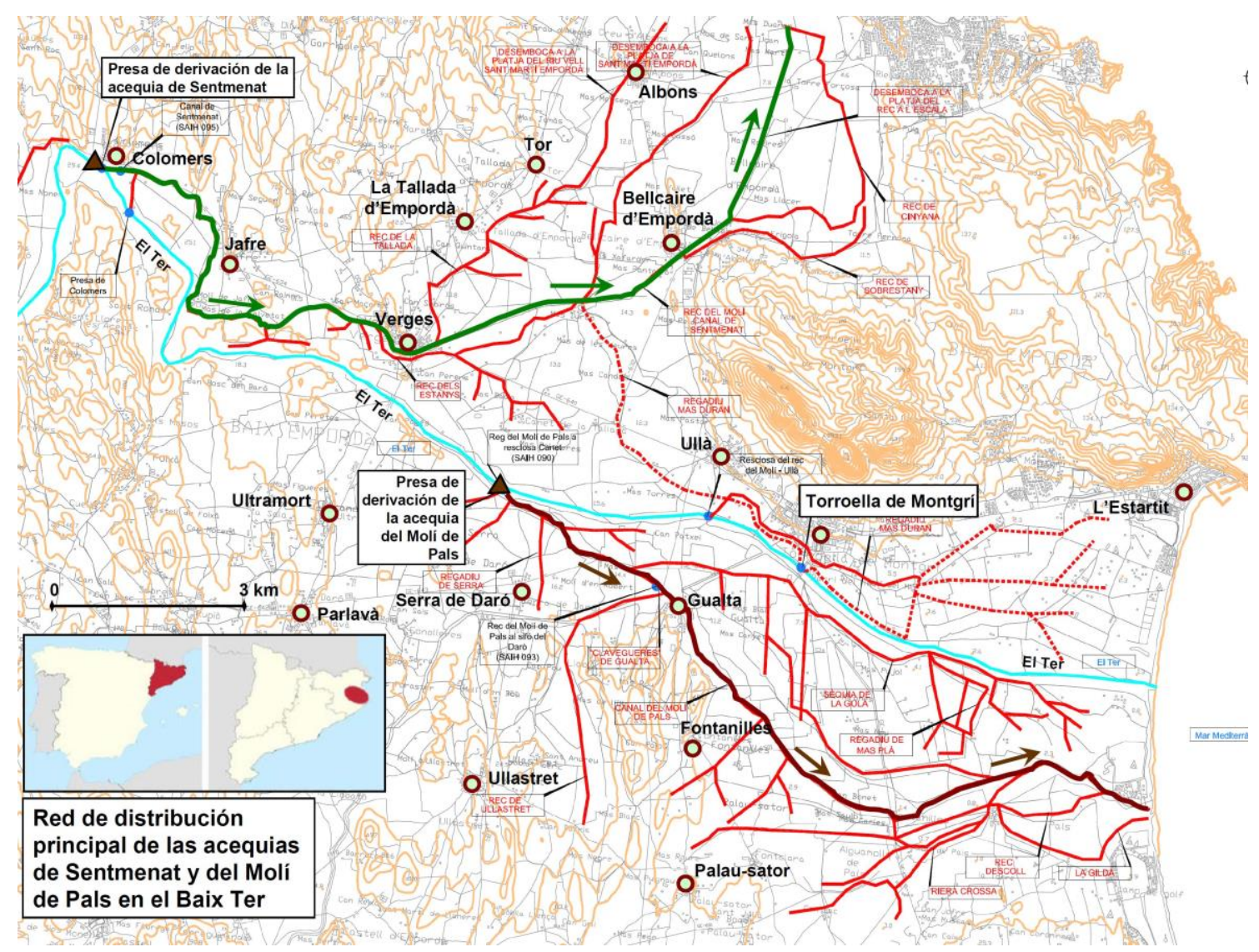

Fig. 2. Trazado de las acequias de Sentmenat y del Molí de Pals así como sus ramificaciones $^{2}$

Por otro lado, en el año 1958 se aprueba el trasvase del Ter para satisfacer parte de las necesidades de abastecimiento creciente de Barcelona y de su zona metropolitana, tanto por su crecimiento demográfico como por su industria. Esto va a suponer la construcción del sistema de grandes embalses Sau-Susqueda-El Pasteral, ubicado en su curso medio. De éste último partirá el canal diseñado a tal efecto para conducir un caudal máximo de $8 \mathrm{~m}^{3} / \mathrm{s}$; por tanto, hasta $252,3 \mathrm{hm}^{3}$ anuales. De hecho, los embalses se promueven, también, con el pretexto de consolidar y aumentar los regadíos del Baix Ter. Las aguas del trasvase del Ter llegan a la ciudad condal en 1966. Por lo que se refiere a los regadíos del Baix Ter, en el año 1967 se concluye una nueva presa en Colomers con una longitud de coronación de 103 metros, con una altura desde cimientos de $18 \mathrm{~m}$. y una capacidad de $1,10 \mathrm{hm}^{3}$. De este flamante azud debían partir los dos nuevos canales principales de regadío (izquierda y derecha del Baix Ter). La puesta en servicio de esa infraestructura hubiese propiciado la substitución de los dos canales históricos existentes. Sin embargo, esto no ha sido así ya que los canales principales no se ejecutaron y la presa nunca ha llegado a utilizarse para tal fin. Por tanto, contra pronóstico, los canales históricos prosiguieron manteniendo su cometido pese al intento de modernización de las infraestructuras.

Por la margen izquierda del Ter, el canal de Sentmenat discurre en sentido de oeste a este. La captación de agua se sitúa en la localidad de Colomers, antes citada. Este canal tiene una

\footnotetext{
${ }^{2}$ Fuente: Agencia Catalana del Agua (2003): Planificació de l'espai fluvial de les conques del Baix Ter, Barcelona, Generalitat de Catalunya.
} 
longitud aproximada de 19,5 $\mathrm{km}$ y transcurre por los municipios de Colomers, Jafre, Verges, La Tallada, Bellcaire d'Empordà y L'Escala. Aguas abajo de Verges el canal se divide en dos ramales: el ramal de la Tallada-Tor-Viladamat, que desemboca en la playa de la acequia del Molí, y los ramales del Mas Duran y del canal Madral, que desembocan en la presa de Ullà. El caudal del canal de Sentmenat en su punto de captación es de $3,45 \mathrm{~m}^{3} / \mathrm{s}$. Actualmente riega 3.030 ha, agrupa a 1.500 usuarios y es de titularidad privada. La entidad que hasta el presente ha gestionado este canal es la Comunidad de Regantes de la presa de Colomers. Se creó en 1975 e integra las colectividades de regantes de Mas Duran, del Abremador de Bellcaire, los Regantes del Molí Nou y la colectividad de la acequia de l'Estany de Verges.

Por la margen derecha, la acequia del Molí de Pals deriva las aguas del río a través de la presa de Canet. El canal tiene una longitud aproximada de $10,5 \mathrm{~km}$ y atraviesa los términos municipales de Serra de Daró, Fontanilles, Gualta y Pals. El caudal en su punto de captación es de $3 \mathrm{~m}^{3} / \mathrm{s}$. Actualmente el canal es de propiedad privada. A través de este canal se riegan aproximadamente 3.000 ha situadas en los términos municipales de Pals, Fontanilles, Torroella de Montgrí, Palau-sator, Serra de Daró y Ullastret y aglutina a un total de 475 regantes integrados en la Comunidad de Regantes del Molí de Pals (constituida en el año 1907). El canal transcurre alejándose de la captación en el río Ter en dirección al núcleo de Gualta. Una vez superado, el trazado de la acequia coincide con el antiguo cauce del río Daró y finaliza en una zona de marismas a pocos metros del mar (ver figura 2).

\section{La encrucijada de los canales de irrigación en el Baix Ter. ¿Una multifuncionalidad cuestionada?}

\subsection{La multifuncionalidad de los canales históricos}

En la etapa que arranca en el año 2008 y que conduce hasta la actualidad, las acequias de Sentmenat y del Molí de Pals y muchos de los ramales que de ellas se derivan están experimentando un proceso de profunda transformación, tanto de su morfología como de su funcionalidad (ver figura 3). Ya se ha descrito cómo a lo largo de los últimos siglos los canales de Sentmenat y del Molí de Pals han contribuido a la construcción del paisaje de regadío característico del Baix Ter. Un paisaje agrario que se presenta a los ojos del observador como un mosaico de parcelas agrícolas de pequeño tamaño y con formas geométricas bastante regulares. La densa red de canales, fuertemente ramificada, cumple a menudo una doble función agrícola. Por una parte, distribuye el agua de las acequias hasta los campos de cultivo y, por otra, recarga acuíferos y drena las aguas de escorrentía. 


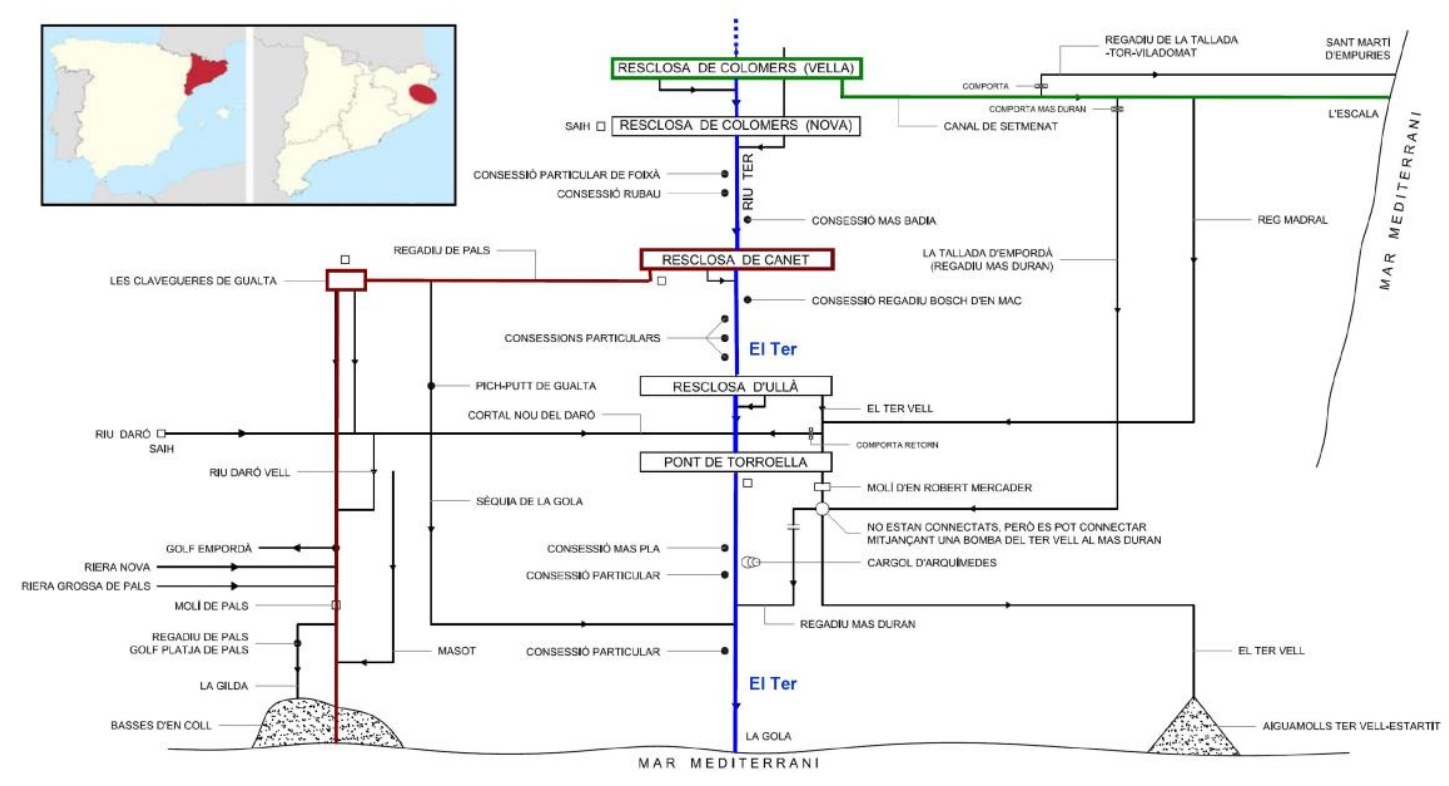

Fig. 3. Esquema de aprovechamientos de las acequias de Sentmenat y del Molí de Pals ${ }^{3}$

La distribución de los cultivos asociada a las comunidades de regantes de las márgenes izquierda y derecha del Baix Ter, según las declaraciones únicas agrarias (DUN) para el año 2013 sumaba una superficie de 7.293 ha. De ellas casi un tercio (un 32,16\%) correspondía al maíz y un $21,24 \%$ al cereal. En tercer lugar se situaban los frutales (14,73\%) especialmente manzanos, pero también melocotoneros y perales- $\mathrm{y}$, a escasa distancia, la alfalfa $(13,98 \%)$ y el arroz $(10,66 \%)$. Estas cinco producciones representaban casi el 93\% del total. Hay un grupo de producciones heterogéneas bastante inferior como la huerta, viveros de plantas, choperas o algunos forrajes que completan el mapa productivo. Aunque el maíz es el cultivo mayoritario en ambas comunidades de regantes (un 33,3\% para la margen izquierda y un 28,1\% para la derecha), las diferencias las marcan fundamentalmente los cultivos del arroz (producido en la parte más baja) y de la alfalfa. Para el caso del arroz, mientras que en la margen derecha supone el $24,5 \%$ de la superficie, en la izquierda se reduce al 14,1\%; del mismo modo, mientras que la alfalfa asciende al 12,8\% de la superficie en la margen derecha, se reduce al $2,4 \%$ en la izquierda. Con una menor diferencia, esta preeminencia también se reproduce para el caso de los frutales $(17,3 \%$ para la margen derecha y $12,4 \%$ para la izquierda). Esto se traduce en el hecho que, por contra, cultivos como los cereales o el propio maíz tengan un mayor peso en la margen izquierda que en la derecha. Las superficies varían su proporción año tras año en función de los precios del mercado esperables y la disponibilidad hídrica que se vaticina en cada campaña. Esta gran variedad de cultivos explica la configuración de un paisaje agrícola heterogéneo, rico en texturas, cromatismos y en constante cambio a lo largo de las estaciones del año.

Los canales ejercen una importante función de recarga de los acuíferos cuando el nivel de estos desciende, bien sea como consecuencia de períodos prolongados de sequía hidrológica, bien sea como resultado de las extracciones de agua subterránea para el regadío o para el abastecimiento urbano (Montaner 2009). Por otra parte, la gran capilaridad de la red y su bajo desnivel también permite que ésta actúe como receptora del exceso de agua

\footnotetext{
${ }^{3}$ Fuente: Agencia Catalana del Agua (2003): Planificació de l'espai fluvial de les conques del Baix Ter, Barcelona, Generalitat de Catalunya.
} 
de los terrenos de cultivo cuando se suceden episodios de lluvias copiosas o incluso inundaciones. Esta función de desagüe de los excedentes hídricos superficiales se ve complementada con la acción de descarga de las aguas del acuífero. Cuando el nivel freático aumenta puede amenazar con inundar durante largos periodos de tiempo las cotas más bajas y aquellos cultivos implantados en cubetas de antiguos lagos o lagunas desecados con finalidades agrícolas (antiguos lagos o lagunas de Verges, Bellcaire, Ullastret, Pals, Boada, etc.) (Matas 1986). La red de acequias asegura el drenaje de estas aguas hacia los cursos superficiales principales evitando efectos negativos como serían el anegamiento de las plantas y la putrefacción de sus raíces.

\begin{tabular}{|c|c|c|c|c|c|c|}
\hline \multirow{2}{*}{ CULTIVOS } & \multicolumn{2}{|c|}{$\begin{array}{c}\text { Molí de Pals } \\
\text { (margen derecha) }\end{array}$} & \multicolumn{2}{c|}{$\begin{array}{c}\text { Presa de Colomers } \\
\text { (margen izquierda) }\end{array}$} & \multicolumn{2}{c|}{ TOTAL } \\
\cline { 2 - 7 } & Supf. (ha) & $\mathbf{\%}$ & Supf. (ha) & $\mathbf{\%}$ & Supf. (ha) & $\%$ \\
\hline Frutales & 465,8 & 17,3 & 608,4 & 12,4 & $\mathbf{1 . 0 7 4 , 2}$ & $\mathbf{1 4 , 7 3}$ \\
\hline Arroz & 661,6 & 24,5 & 115,7 & 14,1 & $\mathbf{7 7 7 , 3}$ & $\mathbf{1 0 , 6 6}$ \\
\hline Alfalfa & 346,2 & 12,8 & 673,2 & 2,4 & $\mathbf{1 . 0 1 9 , 4}$ & $\mathbf{1 3 , 9 8}$ \\
\hline Maíz & 759,0 & 28,1 & $1.586,4$ & 33,3 & $\mathbf{2 3 4 5 , 4}$ & $\mathbf{3 2 , 1 6}$ \\
\hline Cereales & 315,1 & 11,7 & $1.234,1$ & 23,1 & $\mathbf{1 5 4 9 , 2}$ & $\mathbf{2 1 , 2 4}$ \\
\hline Oleaginosas & 16,6 & 0,6 & 72,6 & 1,5 & $\mathbf{8 9 , 2}$ & $\mathbf{1 , 2 2}$ \\
\hline Huerta & 22,6 & 0,8 & 24,8 & 0,5 & $\mathbf{4 7 , 4}$ & $\mathbf{0 , 6 5}$ \\
\hline Chopos & 1,2 & 0,0 & 24,5 & 0,5 & $\mathbf{2 5 , 7}$ & $\mathbf{0 , 3 5}$ \\
\hline Viveros & 0,0 & 0,0 & 21,5 & 0,4 & $\mathbf{2 1 , 5}$ & $\mathbf{0 , 2 9}$ \\
\hline Otros & 109,1 & 4,0 & 234,3 & 11,7 & $\mathbf{3 4 3 , 4}$ & $\mathbf{4 , 7 1}$ \\
\hline TOTAL & $\mathbf{2 . 6 9 7 , 2}$ & $\mathbf{1 0 0}$ & $\mathbf{4 . 5 9 5 , 6}$ & $\mathbf{1 0 0} \%$ & $\mathbf{7 . 2 9 2 , 8}$ & $\mathbf{1 0 0 , 0 0}$ \\
\hline
\end{tabular}

Tabla. 1. Distribución de los cultivos asociada a las comunidades de regantes de las márgenes izquierda y derecha del Baix Ter (año 2013) ${ }^{4}$

Esta doble función de distribución y drenaje que realizan los canales y sus ramificaciones asegura que sus conducciones dispongan de agua de manera casi permanente, lo que permite la colonización vegetal de sus márgenes. Si bien históricamente habían sido los árboles de ribera (olmos, sauces, fresnos, acacias, chopos, etc.) y los frutales (higueras, granados, nogales, etc.) las especies dominantes en estas márgenes, la intensificación de la actividad agrícola en las últimas décadas ha comportado la desaparición de buena parte de esta vegetación, especialmente a lo largo de los canales de menor entidad. Los canales principales de Sentmenat y del Molí de Pals aún conservan tramos de frondosa vegetación espontánea, convirtiéndose en auténticos oasis de ambientes frescos y sombríos en verano.

El patrón paisajístico resultante de esta combinación equilibrada entre campos de cultivo, vegetación espontánea y canales de riego tiene un gran interés, no sólo estético, sino también porque permite la presencia de múltiples especies y hábitats. En concreto, se pueden encontrar hasta cinco hábitats de interés comunitario no prioritario en las acequias, todos ellos vinculados a los ambientes húmedos. Destaca la presencia de varias especies de náyades o mejillones de agua, algunas de ellas autóctonas y protegidas, como es el caso de Union elongatulus o Potomida littoralis, y otras de alóctonas como Anodonta woodiana (Altaba 1992, Franch et al. 2003, Pou-Rovira et al. 2009). Todas estas especies precisan de agua

\footnotetext{
4 Fuente: Declaraciones únicas agrarias (DUN) para 2013. Departamento de Agricultura, Ganadería, Pesca, Alimentación y Medio Natural (Generalitat de Catalunya)
} 
permanente y su ciclo reproductivo requiere de la presencia de especies de peces a las que parasitar con sus larvas. Las especies autóctonas parasitan especies de pez también autóctonas, como la babosa de río (Salaria fluviatilis) o el espinoso (Gasterosteus aculeatus), que a su vez están siendo amenazadas por especies introducidas como la carpa o la perca (Pozo y Rovira et al. 2007, Gómez y Araujo 2008). Otra especie acuática propia de los canales objeto de estudio es la anguila (Anguilla anguilla), diezmada en el Ter debido al reducido caudal que suele llegar a la desembocadura del río y que dificulta que las angulas remonten aguas arriba y se repartan por la red de los canales. Otra especie que también aprovecha la red de canales para colonizar el territorio después de su reintroducción en el Parc Natural dels Aiguamolls de l'Empordà es la nutria (Lutra lutra). En los últimos años se ha detectado su presencia en los tramos de canal más caudalosos lo que ha hecho posible que el canal de Sentmenat tenga el reconocimiento de corredor biológico en el Pla Director Territorial de l'Empordà y también su inclusión en el Plan de conservación de la nutria. Valores ecológicos parecidos se le reconocen al canal del Molí, incluido en el Inventari de Zones Humides de Catalunya por su función de conector entre el Espacio de Interés Natural (EIN) de la Illa de Canet y el EIN Basses d'en Coll. Todos estos valores ecológicos de los tramos finales de ambos canales han justificado su inclusión en el recientemente creado Parc Natural del Montgrí, les Medes i el Baix Ter.

Por desgracia, algunas de las pequeñas poblaciones de la llanura del Empordà continúan vertiendo sus aguas grises, sin tratar o escasamente tratadas, en los cursos situación va camino de ser corregida.

Por último, cabe destacar que en los dos canales tratados también se localizan varios elementos patrimoniales vinculados a los diversos usos o aprovechamientos históricos. La mayoría de ellos se encuentra actualmente en desuso y/o en un estado de conservación muy precario. Los molinos, junto a los lavaderos públicos y las presas desde donde se desvía el agua del río hacia los canales, representan el patrimonio cultural más singular vinculado a los canales. En el canal de Sentmenat se encuentran los molinos de Jafre, Verges, Bellcaire y La Escala, mientra en la acequia del Molí de Pals destacan los molinos de Gualta y el Molí de Pals. Algunos de estos molinos están incluidos en el Inventari del Patrimoni Arquitectònic de Catalunya. Inicialmente eran molinos harineros, excepto el de Pals, que era arrocero. En la actualidad se mantiene la titularidad privada de todos ellos, aunque algunas administraciones públicas han mostrado interés en adquirirlos y transformarlos en equipamientos públicos que integren diversos usos. El molino arrocero de Pals (ver figura 4), también de propiedad privada, es el único que está en funcionamiento y, además, ofrece visitas guiadas encaminadas a divulgar este interesante elemento patrimonial ligado al cultivo del arroz. Por último, cabe añadir que algunos ayuntamientos del Baix Ter han promovido la declaración de Bé Cultural d'Interès Local (BCIL) de algunos tramos del canal de Sentmenat, concretamente en Verges y Jafre, y de la acequia del Molí de Pals, en el término municipal de Gualta. 


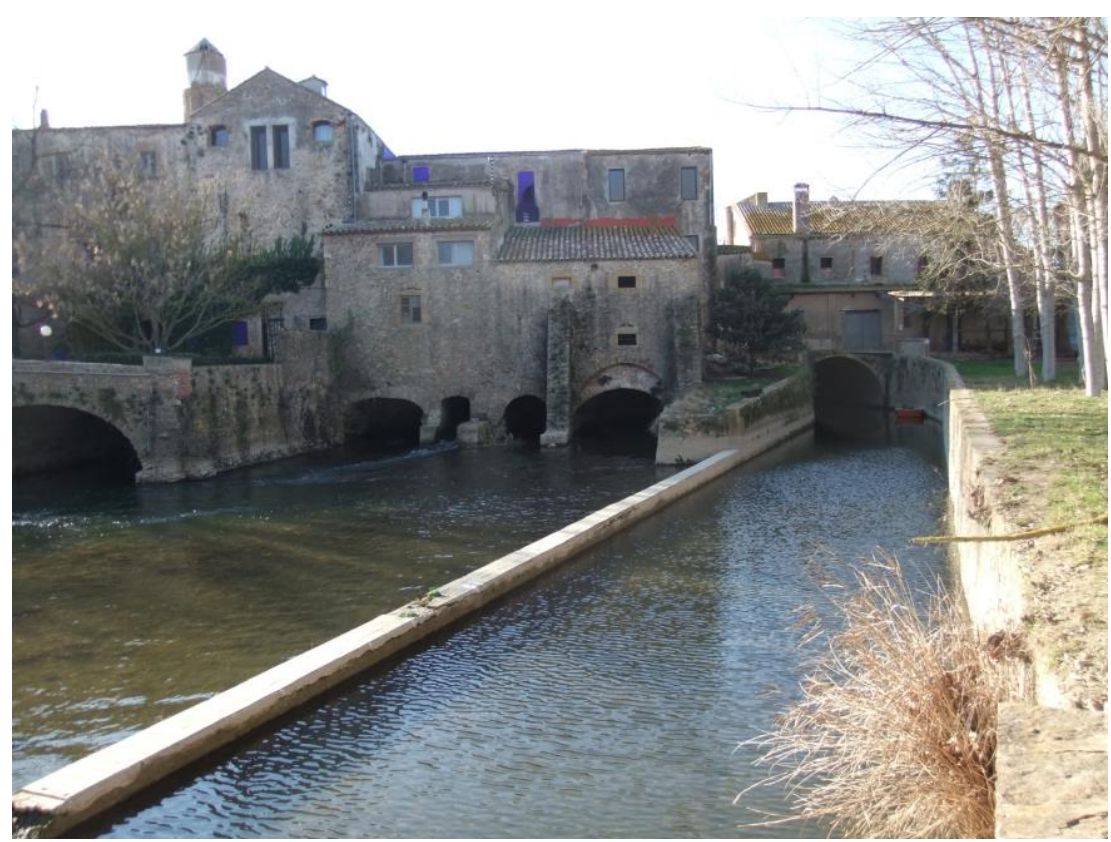

Fig. 4. El molino arrocero de Pals, elemento patrimonial destacado que da nombre a su acequia ${ }^{5}$

En definitiva, los canales de Sentmenat y del Molí de Pals reúnen un conjunto de características y elementos que los convierten en valiosos depositarios de patrimonio cultural e histórico, al tiempo que aglutinan unos usos y funciones que podríamos resumir en diez puntos o aspectos: recogida de aguas de escorrentía superficial; recogida de aguas de retorno del canal; drenaje de las aguas freáticas de la zona próxima a su trazado; distribución de agua para el riego; distribución de agua para los molinos (aunque la mayoría estén fuera de servicio); función sanitaria de evacuación de aguas residuales, producción de energía hidroeléctrica, función ecológica como conectores y hábitats para la biodiversidad y función paisajística.

\subsection{Las obras de modernización y sus efectos sobre la multifuncionalidad de los canales}

Sin embargo, la riqueza patrimonial y la multifuncionalidad intrínseca de los canales que se ha descrito, ha sido profundamente modificada por las obras de modernización y soterramiento de ambos canales. Las obras, desarrolladas entre los años 2009 y 2012, han implicado la colocación de tubos, de secciones diversas, en su mayoría enterradas en un trazado paralelo al de las acequias históricas, por donde el agua ya circula y se distribuye para el riego de las parcelas de cultivo.

El proyecto, finalizado en términos generales en el año 2012, se puso en funcionamiento por primera vez durante el verano del año siguiente. Las obras de modernización han costado 14 millones de euros para la sección correspondiente a la comunidad de regantes de la presa de Colomers y 16 millones para la comunidad de regantes del Molí de Pals. Fueron financiados al 50\% por la Unión Europea y la Sociedad Estatal de Infraestructuras Agrarias (SEIASA), un 33\% por el gobierno autónomo de la Generalitat de Catalunya y el $17 \%$ restante por las respectivas comunidades de regantes (ver figura 5). Las obras no solo contemplaban el soterramiento de los canales principales sino el de la red secundaria de

\footnotetext{
${ }^{5}$ Fuente: David Pavón $(28 / 01 / 2012)$
} 
distribución hasta alcanzar las parcelas agrícolas. Precisamente es esta parte de la ejecución la que está sufriendo algunos retrasos por las restricciones presupuestarias derivadas del cambio de ciclo económico, que dificulta la obtención de las ayudas para que los regantes acometan su ejecución. En el caso de la margen izquierda, en junio de 2014, la modernización de la red secundaria se había realizado en unas 1.400 hectáreas, es decir, alrededor de un tercio de su superficie.

Los objetivos que persiguen estas actuaciones son diversos. En primer lugar, se ha dado respuesta a la demanda largamente formulada por las comunidades de regantes de ambas márgenes del Ter, que consideran que las filtraciones de los cauces de tierra de los canales disminuyen el caudal de agua que llega a los campos, desaprovechando parte del volumen que les otorga la concesión. No se ha realizado ningún estudio completo sobre las tasas de infiltración de agua desde los actuales canales hacia los acuíferos del Baix Ter, pero en la memoria del proyecto constructivo se estima que la impermeabilización puede llegar a ahorrar un total de unos $7 \mathrm{hm}^{3}$ de agua anuales (entre 3-4 $\mathrm{hm}^{3}$ /año en cada uno de los canales). Este ahorro podría ir dirigido desde la ampliación de nuevos regadíos al mantenimiento del caudal ecológico del río o de las propias acequias históricas.

En algunas ocasiones los representantes de las comunidades de regantes también han señalado los elevados costes que implica el mantenimiento del buen estado de los cauces de las acequias y sus ramificaciones. En la mayoría de los casos las estructuras son de tierra y por tanto presentan un aspecto naturalizado, con un rápido crecimiento de las cañas y la vegetación de ribera que hay que eliminar periódicamente. También existen problemas de subsidencia de los márgenes en algunos tramos que se han visto erosionados por las aguas. Se espera que los costes de mantenimiento de la nueva canalización sean menores a los de desbroce y reparación de roturas de las acequias históricas.

En tercer lugar, el proyecto constructivo de mejora del regadío de la acequia del Molí de Pals contempla la posibilidad de ampliar la superficie irrigada por el canal mediante la construcción de nuevos ramales que permitan poner en regadío nuevos terrenos. La sequía que durante los años 2007 y 2008 afectó Cataluña también fue utilizada como argumento para acelerar la ejecución de estos proyectos. En periodos de escasez de agua para el regadío del Baix Ter, como el de los mencionados años, se impone la necesidad de establecer turnos entre los comuneros para el aprovechamiento óptimo de las aguas. La nueva configuración de los canales ha de permitir a las comunidades de regantes un mayor control sobre el uso que harán los usuarios y, sobretodo, ha de garantizar la llegada de suficiente caudal a los tramos finales.

En conjunto, desde el punto de vista de la percepción y valoración que realizan los diversos agentes sociales concernidos en esta actuación, las opiniones son muchas y diversas. A ojos de algunos sectores sociales estas obras suponen una disgregación de las múltiples funciones que los canales de Sentmenat y del Molí de Pals han realizado en los últimos siglos y que les han conferido su riqueza y valor. Desde el punto de vista de la administración pública competente en las políticas de regadío, por contra, esta actuación constituye un paso adelante en el impulso de las políticas de eficiencia y ahorro de agua para usos agrícolas. Para los gestores del ámbito agrario se percibe como una ganancia de libertad a la hora de hacer una gestión de las aguas plenamente focalizada en su función productiva de irrigación de los cultivos. Paralelamente, se considera que la actuación es un estímulo para los municipios que aún vierten aguas en las acequias, obligándoles a adoptar medidas de saneamiento adecuadas. Por último, se dejan los canales superficiales, ya en desuso, para que los responsables de medio ambiente puedan aplicar las políticas de 
conservación que consideren oportunas sin interferir con las otras áreas de la gestión pública.

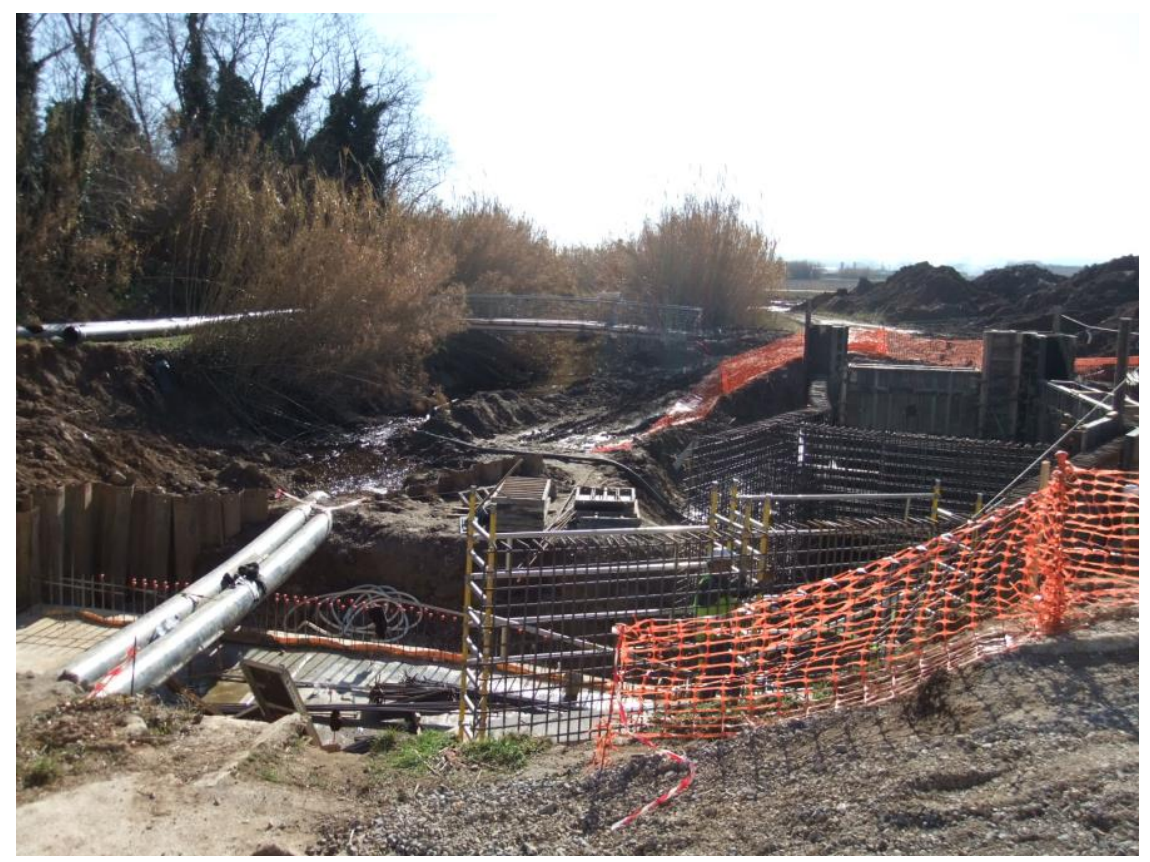

Fig. 5. Construcción de la nueva conducción para los riegos, a la derecha de la acequia histórica del Molí de Pals, en el punto de derivación de sus caudales respecto al propio río Ter (arbolado en la izquierda de la imagen). Mientras las obras se ejecutaban, unos tubos provisionales permitían que el agua continuara discurriendo por la acequia histórica a cielo abierto ${ }^{6}$.

Como consecuencia de esta obra de canalización, los canales históricos dejan de tener el uso prioritario actual de transporte y distribución de agua para el regadío. La entrada en funcionamiento de la canalización de las acequias provocará una disminución de los caudales circulantes derivada de la pérdida de su función de canal agrícola. Según la declaración de impacto ambiental de los proyectos de canalización de las acequias (BOE núm. 286 del 29/10/2007 y BOE núm. 8 del 9/01/08), habrá que dejar un caudal de mantenimiento de $0,3 \mathrm{~m} 3 / \mathrm{s}$ en el canal de Sentmenat y de $0,2 \mathrm{~m}^{3} / \mathrm{s}$ en el canal del Molí de Pals, ajustándolos en función de la respuesta real de los ecosistemas o de la piezometría local.

Pero si bien hasta ahora el mantenimiento de los canales históricos ha sido asumido en buena medida por las Comunidades de Regantes (Comunitat de Regants de la Presa de Colomers y la Comunitat de Regants del Molí de Pals), ¿qué pasará con estos canales históricos ahora que el funcionamiento de la nueva infraestructura ya es una realidad? Si, como parecen reconocer la mayoría de agentes sociales vinculados se considera necesario su mantenimiento para poder conservar sus valores socioambientales, ¿quién y cómo asumirá esta gestión?

\footnotetext{
${ }^{6}$ Fuente: David Pavón (28/01/2012)
} 
Ya en 2008 el Consorcio Alba-Ter (actualmente Consorcio del Ter) ${ }^{7}$, ante la aprobación de los respectivos proyectos y a petición del Departamento de Agricultura, Alimentación y Acción Rural de la Generalitat de Catalunya, elabora el "Estudio del mantenimiento y de los nuevos usos del Rec del Molí de Pals y del Rec de Sentmenat en el Baix Ter". Este documento debía fijar las directrices para valorar las actuaciones necesarias para garantizar la conservación de los aspectos ambientales, ecológicos y culturales de los riegos históricos y proponer nuevos usos una vez entrase en funcionamiento la canalización de los riegos destinada a la mejora de los regadíos del Baix Ter. El estudio constaba de dos propuestas de actuación. La primera se refería exclusivamente al mantenimiento ordinario de los dos canales históricos, una vez entrasen en servicio las obras de modernización. La segunda contemplaba, además, un aprovechamiento educativo, recreativo y turístico que permitiese al acercamiento de los ciudadanos a su entorno y dar a conocer, así, sus valores ambientales, ecológicos, paisajísticos y culturales. La primera propuesta se centraba, básicamente, en la desbrozada de la caña (Arundo donax) y en la gestión de sus restos vegetales practicada de forma anual; también en el dragado y reperfilado selectivo de los taludes de los canales, siempre que no afectase a determinadas especies que tienen su hábitat en ellos o en el lecho. La segunda propuesta, además de estas actuaciones, recogía el diseño de unos itinerarios a pie y en bicicleta que tuviesen como eje los canales, incluyéndose aquí señalización, plafones informativos y su articulación con otros itinerarios próximos existentes. Mientras que para la primera opción se estipulaba un presupuesto orientativo de 52.649 euros, para la segunda ascendía a 72.845 euros. Se debe añadir a esta suma los costes de mantenimiento periódico. Por tanto se trataba de unas cifras que, aunque no eran insignificantes sí resultaban discretas y ajustadas si se comparaba con el montante del presupuesto total de las obras en los dos canales.

\section{A modo de conclusión: unas perspectivas de futuro incierto pero con posibilidades de desarrollo}

Con la ejecución de las obras principales ya finalizadas, quedan muchas incógnitas por resolver en relación a la futura funcionalidad de los canales de Sentmenat y del Molí de Pals, así como a su papel en la configuración del mosaico agrícola del Baix Ter. Vaya por delante el reconocimiento al sector agrario, por los esfuerzos llevados a cabo por promover medidas para aumentar la eficiencia y el ahorro en el riego agrícola y que se ven acompañados por las investigaciones desarrolladas por entidades como el IRTA (Institut de Recerca i Tecnologia Agroalimentàries) con presencia en el propio Baix Ter (centro experimental de Mas Badia).

Durante los últimos años la implementación, a diversas escalas, de nueva legislación e instrumentos de gestión que se focalizan en aspectos como los recursos hídricos, el espacio agrario, la protección del entorno o del paisaje debieran redundar en un mayor encaje de los antiguos canales ante el nuevo escenario dibujado por la modernización del regadío. Se ha de pensar en las directrices establecidas, a nivel europeo, por la Directiva Marco del Agua (año 2000) con un objetivo fundamental como el de conseguir un buen estado ecológico para las masas de agua y con un calendario que fija, el año 2015, como un primer

\footnotetext{
${ }^{7}$ Entidad pública de carácter asociativo con personalidad jurídica propia y que aglutina a una parte muy significativa de los municipios ribereños de la cuenca del Ter. Crea y gestiona servicios o actividades de interés común, partiendo siempre de la iniciativa local e incidiendo, fundamentalmente, en cuatro ámbitos de actuación: patrimonio natural, patrimonio cultural, promoción económica y turismo, y comunicación y sensibilización. El objetivo estratégico del Consorcio es impulsar el desarrollo territorial del espacio fluvial desde la iniciativa local.
} 
momento para la evaluación de estos objetivos. Estas directrices han tenido su traslación en Catalunya en la redacción del plan de gestión de las cuencas internas (aprobado en 2010) o en el programa de los caudales de mantenimiento. Por tanto, no parece consecuente que la ejecución de unas obras de elevado coste, que persiguen el aumento en la eficiencia del riego y que cuentan con el apoyo de la financiación europea y de las administraciones estatal y autonómica desatiendan un aspecto como el de la conservación de los canales el cual debería estar contemplado, a todos los efectos, en el propio proyecto. Desde esta óptica resulta poco consecuente que una propuesta de gestión como la que sugiere el estudio del Consorcio del Ter del año 2008 no haya sido implementada; más aún cuando los proyectos de los canales ya han sido ejecutados. En la misma línea, la Política Agraria Comunitaria (PAC), a través de sus diversos instrumentos, en los últimos tiempos, ha venido introduciendo planteamientos favorables a reforzar la dimensión ambiental de las prácticas agrícolas. En el caso que nos ocupa, más allá de la eficiencia hídrica aplicada a la irrigación, parece razonable que la perspectiva que la PAC pone encima de la mesa alcance también al propio funcionamiento de los canales históricos, por todas las implicaciones ambientales y por su vínculo con el espacio agrario en el que se insieren.

Desde la óptica del paisaje toma especial relevancia la firma del Convenio Europeo del Paisaje (año 2000), que marca el camino que han de seguir los estados miembros del Consejo de Europa para fomentar la conservación y la mejora de la extraordinaria variedad y riqueza de los paisajes del continente, especialmente de los más degradados. En el ámbito catalán tiene su traslación con la promulgación de la Ley del paisaje de Catalunya, aprobada en 2005, y que contempla una herramienta, como los catálogos del paisaje, para conocer la riqueza, evolución y propuesta de mejora de dichos paisajes. La redacción de estos catálogos ha sido dirigida por el Observatorio del Paisaje de Catalunya, creado en 2004. En el caso de las comarcas de Girona, el documento en cuestión fue aprobado por el gobierno autónomo en el año 2010. Dentro de este catálogo se reconocía el Baix Ter como una unidad de paisaje específica, con unos criterios y acciones de protección, también específicos. Entre los criterios de protección se reconocía expresamente a los canales históricos como elementos estructuradores del paisaje y la necesidad de "mantener el patrimonio civil y paisajistico vinculado a los canales y a las infraestructuras hidráulicas del EmpordanetBaix Ter, respetando, en la medida de lo posible, su continuidad funcional, manteniéndolos descubiertos y con un tratamiento paisajístico adecuado. En caso de las posibles transformaciones a acometer en las explotaciones agrícolas, las actuaciones deben seguir las pautas propias de los paisajes agrarios preexistentes" (ver figura 6). Unos criterios, no obstante, que al igual que en todas las unidades de paisaje, no cuentan con una fuerza legal vinculante, sino propositiva.

A falta de un estudio de impacto ambiental que planifique la gestión del agua una vez que las obras ya han entrado en funcionamiento, la resolución a estos interrogantes depende, en buena medida, de cual sea el uso que se otorgue al volumen de agua que la impermeabilización debe permitir ahorrar. A nuestro parecer, se vislumbran tres opciones posibles (Ribas et al. 2012a y 2012b):

- Mantenimiento de un caudal ecológico que posibilite la conservación de los valores naturales, paisajísticos y de los servicios ambientales aportados por las aguas superficiales y la recarga de los acuíferos. Sin embargo, y paradójicamente, en años secos, el cumplimiento de los caudales mínimos impuestos por la declaración de impacto ambiental puede suponer la necesidad de derivar hacia los canales un volumen total de unos $15 \mathrm{hm} 3$ de agua, una cantidad mayor a la que se estima que puede ahorrar anualmente la ejecución de la canalización. 


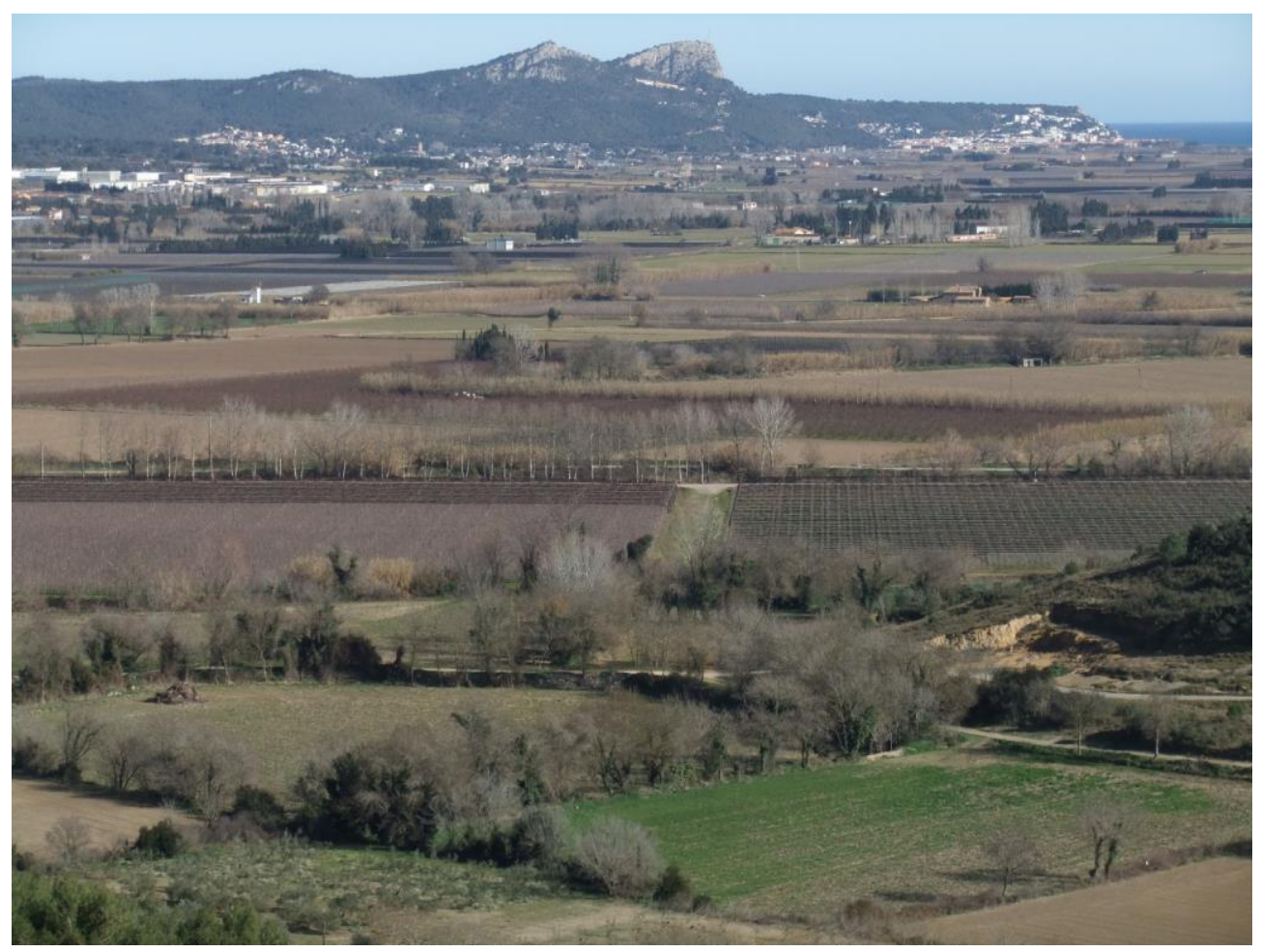

Fig. 6. Panorámica parcial de los regadíos del Baix Ter, des del Puig de la Font Pasquala (92 m.), en Gualta ${ }^{8}$

- Ampliación de las zonas irrigadas en el Baix Ter. Esta opción es técnicamente viable con la nueva configuración del canal de Molí de Pals, pero poco sostenible desde el punto de vista de la gestión de los regadíos en Catalunya. De acuerdo con los escenarios climáticos y de demanda de agua para diferentes usos, se considera que la planificación de regadíos vigente en Cataluña ni siquiera podrá cubrir las demandas agrícolas actuales a medio plazo (Consejo Asesor para el Desarrollo Sostenible -CADS-, 2010).

- Reserva y derivación de las aguas a las redes de abastecimiento de agua en alta de varios municipios de la Costa Brava y del área metropolitana de Barcelona en épocas de sequía. Esta es la única opción que supondría la deslocalización de unos recursos hídricos que históricamente han ido destinados al Baix Ter, lo que podría generar tensiones y conflictividad entre diferentes sectores y territorios en un contexto social y político en el que se han adquirido compromisos de reducir el trasvase de agua del Ter a otras cuencas; un compromiso puesto en cuarentena ante la coyuntura desfavorable de crisis económica.

Los proyectos de modernización ignoran una realidad socioambiental que escapa a la simple lógica de la eficiencia. Como en el caso del Baix Ter, muchos paisajes del agua de la península se han desarrollado a partir de las ineficiencias de los sistemas de riego. Asimismo, muchos labradores, especialmente en las huertas mediterráneas, han podido regar gracias a los retornos de agua generados por el despilfarro que supone el riego a manta. Por la misma razón, los canales son un hábitat húmedo donde múltiples especies vegetales y animales encuentran el refugio que les ha permitido sobrevivir hasta nuestros días. Esta naturaleza históricamente producida es precisamente el gran valor que se les

\footnotetext{
${ }^{8}$ Fuente: David Pavón (28/01/2012)
} 
reconoce a muchos canales y acequias. Antes de que sea demasiado tarde, hay que incorporarlos en los listados de elementos de especial protección ambiental y patrimonial de los numerosos instrumentos de planificación y gestión territorial y urbanística que han proliferado en los últimos años en esta parte de territorio, desde el Pla d'Espais Fluvials del Baix Ter, el Pla Director Territorial de l'Empordà, la Agenda 21 del Baix Ter, el Parc Natural del Montgrí, Illes Medes i Baix Ter, la Red Natura 2000 y los respectivos planes urbanísticos municipales. Esperemos que todo ello sirva, con suficiente fuerza ejecutiva, para conservar los múltiples valores culturales y naturales con los que han llegado a nuestros días.

Un aspecto favorable para la gobernanza de los recursos hídricos en la zona ha sido la materialización de la Comunidad de Usuarios de Aguas Superficiales y Subterráneas del Baix Ter, integrada por 39 ayuntamientos y alrededor de 1.200 usuarios. Esta entidad se creó, inicialmente, en la primavera de 2008 , a raíz del episodio de grave sequía que se vivía entonces no solo en el área de estudio sino en buena parte de Catalunya. Gracias a este ente, los ayuntamientos, las empresas y los particulares con derecho a utilizar un caudal determinado con carácter colectivo deberían poder participar directamente en la gestión de los recursos hídricos. Así, la junta recoge como un objetivo fundamental suyo la promoción del uso racional del agua para resolver la sobreexplotación, la recarga, la contaminación y la intrusión marina que sufre el Ter. Aquí se incluyen medidas de eficiencia en el riego, puntos de control de la salinidad, mejora en la circulación de los caudales, etc. En reunión celebrada el 26 de junio de 2014 se aprobaron los estatutos elaborados por la Comisión Rectora, un trámite pendiente para activar legalmente la entidad. Será conveniente estar atentos a la evolución de la Comunidad y a su traducción en el territorio analizado.

\section{Referencias}

Agencia Catalana del Agua (2003): Planificació de l'espai fluvial de les conques del Baix Ter, Barcelona, Generalitat de Catalunya.

Aguilar, A. (1993): La construcció de l'espai rural al Baix Empordà (Tesis doctoral), Barcelona, Universitat Politècnica de Catalunya. Departament d'Urbanisme i Ordenació del Territori. ETS d'Arquitectura de Barcelona.

Albertí, A; Roura, M. (2002): El Ter, un canal o una anella verda?, Papers del Montgrí, 20: 81181.

Altaba, C. R. (1992): La distribució geogràfica i ecològica dels bivalves d'aigua dolça recents dels Països Catalans. Butlletí de la Institució Catalana d'Història Natural, 60, Secció de Zoologia, 9: 77-103.

Autores diversos (2010): Catàleg de paisatge de les Comarques Gironines. Unitat de paisatge 9: Empordanet - Baix Ter (fitxa $i$ cartografia), Observatori del Paisatge, Departament de Política Territorial i Obres Públiques, Generalitat de Catalunya.

Barbaza, Y. (1988): Elpaisatge bumà de la Costa Brava, Barcelona, Edicions 62, 2 vols.

CADS - Consell Assessor per al Desenvolupament Sostenible (2010): Informe sobre el Pla de regadius de Catalunya. Informe del CADS 7/2010 12 de juliol de 2010. (Disponible en: http://www15.gencat.cat/cads/AppPHP/images/stories/informes/2010/informe 7201 0.pdf.). 
Consorci Alba-Ter (2004-2005): Inventari del patrimoni cultural vinculat als usos de l'aigua dels rius Ter $i$ Freser. Salt-Manlleu.

Consorci Alba-Ter (2008): Estudi del manteniment $i$ dels nous usos del Rec del Moli del Pals $i$ del Rec de Sentmenat al Baix Ter. Salt-Manlleu. Documento técnico.

Donat, L.; Solà, X. (2003): Els molins, Quaderns de la Revista de Girona, 108. Girona, Diputació de Girona i Caixa de Girona.

Franch, M.; Boix, D.; Sala, J. (2003): Localitzacions de Nàiades (Mollusca: Bivalvia:

Unionoida) a les conques de la Muga, de la Tordera i del Ter, Scientia gerundensis, 26: 5-7.

Gómez, I. y Araujo, R. (2008): Channels and ditches as the last shelter for freshwater mussels. The case of M. auricularia and other naiads at the mid Ebro River basin, Spain, Aquatic Conservation: Marine and Freshwater Ecosystems, 18: 658-670.

IGREMAP, S.L.P. (2010): Pla de Regadius de Catalunya 2008-20, Departament d'Agricultura, Alimentació i Acció Rural (Generalitat de Catalunya) y REGSA, Barcelona.

IRTA Mas Badia (2013): Pla d'acció per a la millora de l'eficiència del reg 2013, Departament d'Agricultura, Ramaderia, Pesca, Alimentació i Medi Natural (Generalitat de Catalunya).

Lefebvre, H. (1991): The Production of Space, Blackwell, Oxford.

Matas, J. (1986): Els estanys eixuts. Quaderns de la Revista de Girona, 7. Girona, Diputació de Girona i Caixa d'Estalvis Provincial.

Montaner, J. (2009): Els aqüífers del Baix Ter. Papers del Montgrí, 30: 14-16.

Pella i Forgas, J. (1883): Historia del Ampurdán: estudio de la civilización en las comarcas del noreste de Cataluña, Barcelona: Luis Tasso.

Pou-Rovira, Q.; Araujo, R.; Boix, D.; Clavero, M.; Feo, C.; Ordeix, M.; Zamora, L. (2009): Presence of the alien chinese pond mussel Anodonta woodiana (Lea, 1834) (Bivalvia, Unionidae) in the Iberian Peninsula. Graellsia, 65(1): 67-70.

Pou-Rovira, Q.; Clavero Pineda, M.; Zamora Hernández, LL. (2007): Estat de conservació de l'espinós i bavosa de riu. Papers del Montgrí, 28, 55-91.

Quintana, X. (coord.) (2010): Bases tècniques per al correcte funcionament bidrològic de la plana del Baix Ter, Girona: Càtedra d'Ecosistemes Litorals Mediterranis. Universitat de Girona.

Ribas, A.; Llausàs, A.; Saurí, D.; Roset, D. (2012a): Perception et valoration sociale de l'irrigation traditionnelle dans le Bas Ter (Bas Ampurdan, Catalogne), en ASPE, C. (Coord.), De l'eau agricole à l'eau environnmentale. Résistance et adaptation aux nouveaux enjeux de partage de l'eau en Méditerranée. Éditions Quae, París, pp. 199-208. 
Ribas, A.; Llausàs, A.; Saurí, D.; Roset, D. (2012b): El paper dels recs de Sentmenat i del Molí de Pals en la configuració de la plana agrícola del Baix Ter, Estudis d'Història Agrària, 23, 319-334.

Sala, P. (2008): El Catàleg de paisatge de les comarques gironines, Revista de Girona, 250 : $70-75$.

Smith, N (1984): Uneven Development: Nature, Capital, and the production of Space, Blackwell, Oxford.

Soldevila, X. (2007): Entre les aigües i el bosc. Impressions del paisatge medieval a la plana del Baix Ter (segles XII-XIV), en Actes del Congrés: El paisatge, element vertebrador de la identitat empordanesa, vol.II, 345-353. Figueres: Institut d'Estudis Empordanesos.

Swingedouw, E. (1999): Modernity and Hybridity. Nature 'Regeneracionismo' and the Production of the Spanish Waterscape, 1880-1930, Annals of the Association of American Geographers, 89:, vol. 3: 445-465.

Visentin, F. (2014): Canali artificiali, territorialità idraulica e paesaggio. Un studio comparativo tra Veneto, Catalogna e sud-ovest dell'Inghilterra, (tesis doctoral), Dipartimento di Scienze Storiche, Geografiche e dell'antichitá Universitá degli Studi di Padova. 